\title{
EPITELIOMA CALCIFICADO DE MALHERBE
}

\author{
Por los Dres, JULio ESPINOZA s. y JOSE ALTAMLRANo P. \\ Instituto de Anatomia Patofógica del Hospital Manuel Arriarán.
}

Creemos de interés dar a conocer este tipo de tumor tan singular por sus características anátomo-clínicas, ya que se trata de un proceso patológico poco frecuente entre nosotros y a que su incidencia prevalece en los individuos jóvenes.

Vilcken, en 1858, fué el primero que describió este tumor como "un epitelioma cuyas células han sufrido una metarnorfosis regresiva calcárea $y$ cuyo estroma se ha transformado en un verdadern hueso". Pero fué Malherbe, en 1881, quien hizo de él una descripción muy completa y le llamó "epitelioma calcificado".

Aparece en cualquiera edad, pero, según la opinión de numerosos autores, es más frecuente en niños y jóvenes en general. En 40 casos reunidos por Févre, Garling y Palmer, 21 correspondían a niños adolescentes y adultos jóvenes hasta de 30 años, 14 casos se presentaron en individuos de 30 a 50 años y 5 en personas de 50 a 75 años.

Su localización preferente es en la parte alta de la cara, cuello y miembros, en forma de un nódulo duro, indoloro, más bien subcutáneo que intradérmico, sin adherencias a los tejidos profundos ni a la piel y que solevanta a esta última ligeramente. Su tamaño varía desde el de una arveja al de una castaกิa.

La evolución del tumor es muy lenta, permaneciendo después estacionario. Es así cómo generalmente el enfermo consulta por una afección que la pađece desde hace varios o muchos años. En los primeros 10 casos de Malherbe, 9 presentaban el tumor desde hacía 20 años. En casos raros puede ulcerarse e infectarse secundariamente.

El diagnóstico clínico oscila entre ganglio calcificado o quiste sebáceo o fibroma y sólo es el examen histopatológico que permite un diagnóstico exacto, por lo que siempre es un hallazgo del anátomo-patólogo.

Macroscópicamente es bien capsulado, cruje al cortarlo, mostrando una superficie áspera, con focos granulosos o esponjosos, de color amarillento-turbio o dorado. El examen microscópico revela nódulos o trabéculas sólidas de $\in \mathrm{pi}$ telío pavimentoso, de tipo baso o espinocelular, con sus células muy iguales entre sí, con escasas o ninguna carioquinesis. Lo característico de este tumor es la presentación de múltiples focos necróticos y calcificados a nivel de los nódulos epiteliales, transformaciones regresivas que es posible seguir en todas sus gradaciones. Rodeando este tejido epitelial se observa tejido fibroso infiltrado por elementos de inflamación crónica y células gigantes, tipo cuerpo extraño, reacción natural del organismo ante el material necrótico o calcificado que procura eliminar. En algunos casos hay formación de verdaderos focos óseos por metaplasia de las células mesenquimáticas jóvenes del estroma.

Respecto de su pronóstico, todos los autores están de acuerdo en que se trata de un tumor benigno y así también lo afirma el estudio histopatológico. Su extirpación và seguida casi siempre de la 
curación definitiva, salvo raros casos en que se ha producido la recidiva por extirpación incompleta. Por estos motivos, el nombre de "epitelioma" sólo puede referirse a que es un tumor de origen epitelial, pero no "maligno". como es la acepción corriente que los franceses conceden a este término.

Su causa y patogenia han sido muy discutidas. La frecuencia de su aparición en los primeros años de la vida y la existencia de casos francamente congénitos, ha hecho suponer el origen embrionario de este tumor desde la observación de los primeros casos (Virchow y Klebs, Jadassohn y Gónus, etc.), homolcgándolos con los "naevus", o sea, in- driguez, de la Sociedad de Anatomia Normal y Patológica de Chile, ambos durante el año 1943, dados a conocer en sesiones de las Sociedades nombradas, el $1^{\circ}$ de septiembre y el 26 de noviembre, respectivamente.

Zúñiga y Rosselot, đescriben 2 casos, ambos ocurridos en hombres, de 30 años el primero y de un poco más edad el segundo, ambos con una evolución de varios años, indoloro. ubicados en la región pectoral derecha y en el brazo izquierdo respectivamente y cuyos exámenes histopatológicos fueron realizados por el Profesor Croizet. El primero de estos casos fué diagnosticado clínicamente como "ganglio calcificado".

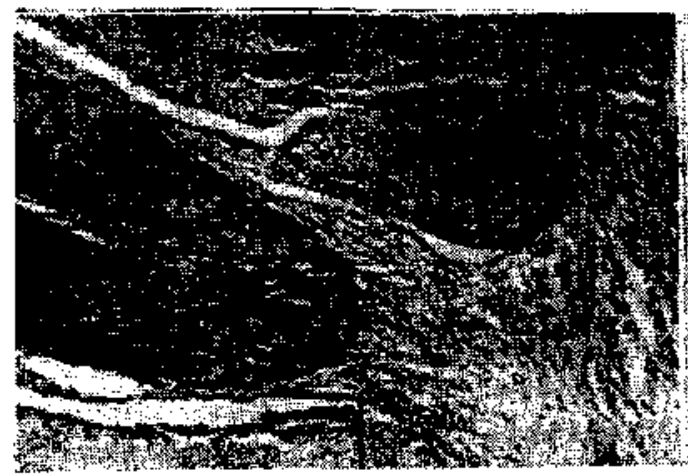

MICROFOTOGRAFIA N" ।

$X$ 60. - Nódulos epiteliomatosos con focos necróticos. A derecha se observa cápsula fibrosa.

clusiones embrionarias de tejidos, indiferenciados o diferenciados, que con posterioridad dan lugar a este tipo de tumor. Otros autores, dentro de esta misma teoría etio-patogénica, creen que se origina de inclușiones de glándulas sebáceas aberrantes (Nurrakann y Firket). La hipótesis de que se trataría de un carcinoma con intensas alteraciones regresivas, ha sido desechada por la gran mayoría de los investigadores.

En una revisión realizada por nosotros, en la literatura nacional de los últimos 10 años y que se refiere al tema que abordamos, encontramos dos trabajos publlcados: uno por los Dres. Zúñiga y Rosselot, de la Sociedad de Cirugía de Chile y el otro por el Dr. Héctor Ro-

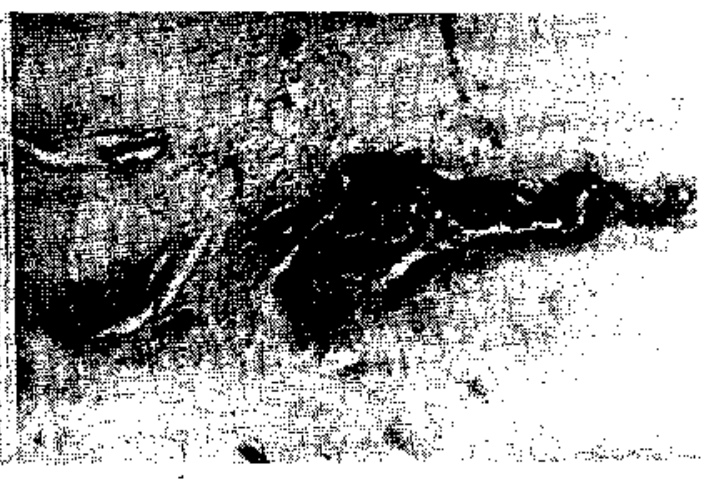

MICROFOTOGRAFIA $N: 2$

$\mathrm{X}$ 60. - - Nódulos necrosados y partialmente calcifitados. rodeados por tejido granulatorio rico en células gígantes tipo cuerpo extraño.

Rodríguez publica 3 casos ocurridos en 2 mujeres (una "adulta" y la otra de 12 años) y 1 hombre (65 años), 2 de ellos ubicados en los miembros superiores y el tercero en el cuero cabelludo.

El caso nuestro que motiva esta presentación, corresponde a una niña de 12 años, que consultó en la Policlínica de Sirugía del Hospital Manuel Arriarán (Obs. Cl. N" 89243/51), pcrque desde hacía 4 meses le apareció una hinchazón cervical izquierda, que crecló más - menos rápldamente. El airujano (Dr. Fernando Torresl comprobó al examen clinico un tumor duro, aplanado, redandeado e indoloro, que seguia los movimientos de la piel y lo operó el 4-VIII-51, enviándolo a nuestro Instituto con el diagnóstico de "Quiste cervical izquierdo".

Recibimos nosotros (blopsia N 220/51) dos trozos de tejido, el mayor de $3 \times 2 \times 1.5 \mathrm{~cm}$ 
y de color rolo y consistencia firme. Al corte era blando, desprendiéndose de su centro numercsos granulitos arenosos y blanquecinos. Microscópicamente se encontraron cordones sóltdos de epitelio pavimentoso de transición, afectos en numerosas zonas de focos necrosados y calcificados. En los nódulos epiteliales fú posible evidenciar algunas carioquinesis tiplcas. El estroma, formado por tejido conjuntlvo infiltrado difusamente por células redondas, revelaba en la proximidad de los focos eptteliales degenerados numerosas células gigantes tipo cuerpo extraño. Todos los tejidos estaban rodeados por una gruesa cápsula fibrosa infiltrada por focoz linfocitarios. (Ver microfotografias Nos. 1 y 2).

\section{Resumen.}

A propósito de un caso de epitelioma calcificado de Malherbe observado por los autores, se hace un resumen de Ia patología de este tumor y se revisa la casuística nacional.

\section{Summary.}

On base of a case of "Epitelioma calcificado" (Malherbe) that authors have found they reassume this tumor's pathology and they revise national casuistic.

\section{Bibliografía.}

DARLER, J. - "Precis de Dermatologie". Paris, Mason et Cie. Editeurs, 1928.

ROSRIGUEZ, H. - "Sobre epitelioma calcificado de Malherbe". Archivas Chilenos de Morfologia, Tomo VII, 1949.

ZUNIGA, R. y ROSSELOT, M. - "Epitelioma benigno calcificado de Malherbe". Rev. Médica de Chile, $\mathbf{N}^{\circ} 11$, nov, de 1943. 